

\title{
ANTIGOS E MODERNOS, 0 FARDO E 0 FIO
}

\author{
Francisco Murari Pires \\ Departamento de História - FFLCH/USP
}

Ao firmar no proêmio de sua obra qual fosse a valia da história que ele narrava, Tucídides adverte contra os apelos que a desviassem pelas veredas sedutoras dos relatos mitificantes (tò mythõdes). Por tais modos narrativos, consagrados por poetas e logógrafos, a narração de histórias sujeitava (e perdia) sua finalidade enquanto memorização de feitos humanos ao sacrificar a expressão da verdade dos acontecimentos em prol da fruição do que era do agrado do público presente a quem fossem contadas. Ordenação da narrativa das ações dos homens pelos efeitos do mito que frustra a valia de suas histórias fazendo desvanecer, pelo deleite fugaz do presente, o alcance perene a que a memória humana almeja por (i)mortalidade. Tucídides, pelo contrário, ordena sua narração pelo primado cognitivo da verdade dos fatos, apreendida graças à acribia de excelência ajuizante por historiador que se fundamenta pela $a u-$ tópsia fenomênica porque se presenciam os acontecimentos. A memorização das ações humanas ganha clarividência pela narração de uma história, a da Guerra dos Peloponésios e Atenienses, então cristalizada como saber. Dado que os homens, pelos modos próprios de sua natureza, assemelham suas ações no curso do tempo histórico, praticando-as tais quais ou análogas às do passado, a história, constituída como ciência clarividente, dispõe sobre ktema es aei (aquisição para sempre). O olhar da história tucidideana volta a plenificação de sua valia para o futuro, quer imediato quer longínquo, por que os homens desta temporalidade a reconheçam no presente de suas ações. A história, por esse entendimento tucidideano, figura essencialmente a instância privilegiada de saber humano, isto é, dos homens e para os homens, presentes e vindouros, de todos os tempos. 
Diz Políbio que é dever do historiador, ao empreender a composição de sua obra, tecer o louvor da história, firmar e reiterar as virtudes mais os benefícios que consagram e, pois, recomendam a todos os homens de todas as épocas a valia do conhecimento histórico. Ele assim o proclamava em Roma antiga, por meados do II século antes da era cristã, justo quando a cidade consolidava seu (suposto ou alegado) destino histórico de senhora do mundo, recém derrotada e aniquilada Cartago, que com ela rivalizava nas pretensões ambiciosas de um tal projeto. Políbio então comemora (mas também adverte), por sua narrativa histórica, a glória do poder imperial, por todas as vicissitudes de benesses (como de malefícios) que, por ele, os vencedores usufruem (mas também sofrem).

Retirado em Sant'Andrea di Percussina, Maquiavel volta o olhar da história para o passado. Pelo circuito dos livros de seu escritório frequenta então a Corte dos antigos, com eles dialogando sobre as questões do Estado. Refletindo sobre esse diálogo com os antigos em privilegiando a eleição da Primeira década de Tito Lívio como interlocutor especial, Maquiavel pondera o alcance do olhar que a história presente volta para o passado, a fim de que se mobilize recíproca interpelação de conhecimentos modernos e antigos sobre os modos porque nela agem os homens.

$\mathrm{O}$ passado antigo que os homens memorizam por suas histórias fulgura imagens de perfeição, ícones de veneração que entesouram, exteriormente a nós mesmos, nossos valores e ideais petrificados, estáticos, como essas estátuas, ou apenas seus fragmentos, que adornam as casas modernas a figurarem modelos de beleza. Os modernos tornam os antigos presentes em suas vidas como (se fossem) deuses, por obras e feitos de grandeza e perfeição tanto mais veneráveis quanto excepcionais, de (ir)realização encerrada no passado, inalcançáveis, impossíveis para os homens do presente. Os antigos figuram na história valendo por heróis, essa ambígua categoria por que se (con)fundem homens e deuses. Assim, adverte Maquiavel, os homens extraviam "o sentido real da história, perdem seu espírito genuíno, substância de que se nutre o nosso". Pois, a história, quer de antigos quer de modernos, os homens a fazem. E os homens de outrora são ainda os de hoje, como também o são "o sol e o céu e os demais elementos, mais sua ordem, rumos e poder". A mímesis do antigo pelo moderno conforma, portanto, o télos da história, seu princípio e fim, sua essência, o bem valioso disponibilizado como o(s) conhecimento(s) virtuoso(s) que ela memoriza.

Eis, diz Maquiavel, sua "descoberta", a senda não trilhada por que se vislumbre o novo continente até então inexplorado, o método inovador de 
reflexão sobre a história, qual seja, uma dialética em que passado antigo e presente moderno mutuamente interpelem suas razões: "Resolvido a salvar os homens deste erro, achei necessário redigir, a propósito de cada um dos livros de Tito Lívio que resistiram à injúria do tempo, uma comparação entre fatos antigos e contemporâneos, de modo a facilitar-lhes a compreensão. Deste modo, meus leitores poderão tirar daqueles livros toda a utilidade que se deve buscar no estudo histórico". E história, consequentemente, de axiologia e teleologia essencialmente política, atinente às questões do Estado: como "ordenar uma república, manter um Estado, governar um reino, comandar exércitos e administrar a guerra, ou distribuir justiça aos cidadãos". História por descortino político e política de profundidade histórica, o saber inovador é assim disponibilizado aos que agenciam os destinos humanos no tempo histórico ("príncipes, repúblicas, capitães, cidadãos"), oferecendo-lhes os "exemplos da Antiguidade" em que devem "apoiar" seus atos, bem discernindo "virtudes contra vícios, a fugir destes e imitar aquelas". Tal o dever do homem honesto, diz Maquiavel: "apontar o caminho do bem".

Algumas décadas depois, meados do século XVI, Jean Bodin inaugura as reflexões do Methodus ad facilem historiarum cognitionem tecendo o elogio da história então concebida como magistra vitae, desdobrando a antiga fórmula originariamente ciceroniana. Por uma figuração metafórica a história é estimada como esplêndido jardim, lugar de natureza cultivada pródiga de virtudes (re) vivificantes. Assim é afirmada a excelência valiosa, benéfica, do saber histórico: figura mestra de vida, fonte de virtudes mais ensinamentos a guiar as condutas e os atos dos homens por uma vida bela, regrada consoante o cânone disposto por suas leis sagradas. História vale por conjunção de moral com arte, por que a virtude seja bela e a beleza virtuosa. História compõe então campo de saber por afinidade e contiguidade com filosofia, ela também definida por similar fórmula tradicional: vitae dux, diretriz de vida. Mas a filosofia assim o é ao ensejo do que a história provê: ao registrar os ditos, os fatos e os ensinamentos do passado a história dispõe a memória exemplar dos atos humanos descortinados em seu horizonte de máxima amplitude moral, quer pelos extremos virtuosos de bens a serem buscados quer pelos viciosos de males a serem evitados.

História constrói, pois, a ponte porque os homens transitam a temporalidade de suas ações, tirando da memória dos fatos passados (verdadeiro tesouro de ensinamentos) a ciência e a razão explicativa do presente, a assim vislumbrar a via por que se adentra o futuro ciente de suas encruzilhadas decisivas, em que 
se bifurcam o caminho do bem, inflamando os homens para por ele trilharem em louvando suas virtuosidades exemplares, contra o do mal, advertindo-os a dele se afastarem em amaldiçoando suas viciosidades degradantes. A história configura, então, para o homem moderno o que o mito do patrocínio da sabedoria de Minerva imaginara para o antigo, assim consagrado pelo destino heróico de Hércules, por que ele optasse entre a virtude e o vício. Tanto mais que a fama imortal a que os homens almejam como justa recompensa que os glorifique impele-os a tomarem a via da excelência virtuosa. Por esta apreciação, a axiologia histórica que Bodin sustenta para a ética do homem moderno, de consonante consciência cristã, diverge daquela que lhe é antes antagônica por seus vezos de paganismo antiquizante como figurada na história anedótica do Sonho de Maquiavel. Mesmo aos malfeitores, assevera Bodin, oprimem as aflições que torturam suas almas pela antevisão da reputação infamante que deixarem na história a denegrir suas almas.

Por meados do século XIX já em sua segunda metade, História Antiga firma-se, ao longo da primeira, como disciplina acadêmica, um dos itens do currículo fundante dos cursos de História. Os novos produtos historiográficos, assim conformados no espírito dessa historicidade de "regime moderno" (François Hartog), germinam também no campo ideológico consagrado ao diálogo com as memórias do mundo antigo, há séculos fertilizado pelos modernos, já desde o Quattrocento italiano. Um, dentre os dois historiadores alemães tradicionalmente celebrados como fundadores da história científica, Barthold Georg Niebuhr, ministra cursos de História Antiga (Vorträge über alte Geschichte) na Universidade de Bonn, uma primeira vez no verão de 1826 e a segunda no inverno de 1829-1830. De 1846 data (os inícios d)a History of Greece de George Grote, e de 1851, a Histoire Grecque de Victor Duruy. Por todos eles, historiadores e suas obras, a presença atuante de uma instância catalisadora da reflexão: os espectros da Revolução Francesa, 1793-4 especialmente. O caso de Niebuhr é emblemático, comportando, algo "romanticamente", desfechos de pathos um tanto "trágico": foi na esteira das aflições com a nova Revolução em França, em julho de 1830, sempre ávido por buscar nos jornais as notícias de seus avanços, que Niebuhr apanhou, de retorno da biblioteca para casa na noite de Natal fria e úmida daquele ano, "o resfriado" que o levou, desde aquela noite, ao leito que só deixaria já morto, a 1 de janeiro do ano seguinte.

No 18 Brumário de Luís Bonaparte, Marx, denunciando o travestimento da obra histórica da Revolução Burguesa então tramado nos anos de 1848-51, 
que fazia da segunda edição do 18 Brumário, pelo sobrinho, a caricatura do feito original, do tio, sentenciara:

Os homens fazem sua própria história, mas não a fazem como querem; não a fazem sob as circunstâncias de sua escolha e sim sob aquelas com que se defrontam diretamente, legadas e transmitidas pelo passado. A tradição de todas as gerações mortas oprime como um pesadelo o cérebro dos vivos. E justamente quando parecem empenhados em revolucionar-se a si e as coisas, em criar algo que jamais existiu, precisamente nesses períodos de crise revolucionária, os homens conjuram ansiosamente em seu auxílio os espíritos do passado, tomando-lhes de empréstimo os nomes, os gritos de guerra e as roupagens, a fim de apresentar a nova cena da história do mundo nesse disfarce tradicional e nessa linguagem emprestada.

Assim, concluiu qual fosse o melhor preceito a por o princípio da última revolução mesma que ele propugnava:

A revolução social do século XIX não pode tirar sua poesia do passado, e sim do futuro. Não pode iniciar sua tarefa enquanto não se despojar de toda veneração supersticiosa do passado. As revoluções anteriores tiveram que lançar mão das recordações da história antiga para se iludirem quanto ao próprio conteúdo. A fim de alcançar seu próprio conteúdo, a revolução do século XIX deve deixar que os mortos enterrem seus mortos.

Mas, na proposição desse princípio revolucionário, assim declaradamente inaugural de verdade histórica, ambicioso de desprender-se das perversas amarras da História, a mesmo reclamar o fim desta, ter-se-ia vislumbrando o éden humano no futuro, previsto por esse fim da história?

Cerca de um século depois, inícios de meados do XX, década de 1950/60. Tempos de "renovada" historicidade, então iniciada por anos de Guerra Fria, e demais sequelas da crise da civilização ocidental diante da falência do Estado liberal selada pela emergência dos totalitarismos. Hannah Arendt dialoga com Marx.

Em Between Past and Future, com data de publicação em 1961, Hannah Arendt tece uma intrigante leitura da filosofia politica de Marx, a nela desvendar as tramas de uma espécie de peripécia, ${ }^{1}$ que teria vingado contra o princípio

\footnotetext{
${ }^{1}$ Peripécia, diz Aristóteles na Poética, é aquela ação trágica que se caracteriza por produzir justamente o efeito e resultado contrário daquele objetivo e propósito a que essa ação em princípio pretendia e justamente almejava. Assim, quando no Édipo Rei de Sófocles, Jocasta intenta tranquilizar o marido, Édipo, então atormentado com as terríveis profecias que o oráculo délfíco de Apolo lhe anunciara de um destino o mais horrendo - assassino do próprio pai e amante da própria mãe -, ela, Jocasta, empenha-se em convencê-lo acerca do valor inócuo que os oráculos
} 
revolucionário disposto por ele em sua obra que, ao que ela diz, "não virou Hegel de cabeça para baixo tanto assim".

Pois, o ideal de sociedade de Marx - por seus dois tópicos sublimados: a eliminação do Estado e a ausência do trabalho - foi, ao que argumenta a trama reflexiva de Hannah Arendt, historicamente realizado pela pólis grega. ${ }^{2}$ Desvanece-se (ou pretende-se desvanecer), pois, por esta reflexão, a exclusividade do fascínio inaugural que a tradição revolucionária, outrora projetada por Marx, avocava para si, para a Revolução Social do século XIX, enquanto obra verdadeiramente demiúrgica a, por fim, alcançar a criação do absolutamente novo na História, daquele algo que nela jamais existiu. Trata-se de um equívoco, dá a entender Arendt, um equívoco que ignora a pólis. ${ }^{3}$

O que essa tradição revolucionária colocara como o fim da História nada mais é então, pela reflexão de Hannah Arendt, paradoxal e ironicamente, o princípio, a pólis grega. É que, argumenta a teórica do pensamento político-

têm, de sua inutilidade, da falsidade mentirosa de sua pretensas previsões. Jocasta conta então a Édipo, seu atual marido, como esse mesmo oráculo apolíneo predissera outrora a morte de Laio, o antigo rei de Tebas e também primeiro marido de Jocasta, às mãos de seu próprio filho. Oráculo totalmente inverídico, afirma ela confiante, pois a única criança que ele, Laio, tivera por filho, dela gerado, morrera ainda recém-nascida, abandonada indefesa às feras selvagens nas montanhas do Cíteron. Não, Laio morreu, sim, mas não pelas mãos desse seu único filho, e sim de salteadores que o atacaram no caminho de Tebas para Delfos, justo na encruzilhada. E o relato da morte de Laio, assim revelado por Jocasta a Édipo, avivou neste ultimo antes lembranças ainda mais angustiantes do que tranquilizantes, pois, tudo o que ela relatara ocorrera também justo com ele, eventos muito similares, em que ele, lá naquela mesma encruzilhada dos caminhos para Tebas e Delfos, matara um viajante, um desconhecido, mas que agora, parecia-lhe, identificava-se com esse antigo rei tebano, de que ele seria consequentemente o assassino. Reiterava-se, ainda mais terrível por tudo o que Jocasta contara, a suspeita da verdade do oráculo!

${ }^{2}$ Vejam-se os comentários no ensaio A condição Humana entre o Sputnik e Prometeu, editado em Mithistoria (Pires, 1999, p. 35-50).

3 "Na filosofia de Marx, que não virou Hegel de cabeça para baixo tanto assim, mas inverteu a tradicional hierarquia entre pensamento e ação, contemplação e trabalho, e Filosofia e Política, o início feito por Platão e Aristóteles demonstra sua vitalidade, ao conduzir Marx a afirmações flagrantemente contraditórias, principalmente na parte de seus ensinamentos usualmente chamada utópica. As mais importantes são suas predições de que, sob as condições de uma humanidade socializada, o Estado desaparecerá, e de que a produtividade do trabalho tornar-se-á tão grande que o trabalho, de alguma forma, abolirá a si mesmo (...) Essas afirmações, além de serem predições, evidentemente contêm o ideal de Marx da melhor forma de sociedade. Como tal, não são utópicas, reproduzindo antes as condições políticas e sociais da mesma cidade-estado ateniense que foi o modelo da experiência para Platão e Aristóteles e, portanto, o fundamento sobre o qual se alicerça a nossa tradição. A pólis ateniense funcionou sem uma divisão entre governantes e governados e não foi, assim, um Estado (...) Os cidadãos atenienses, além disso, eram cidadãos apenas na medida em que possuíssem tempo de lazer, em que tivessem aquela liberdade face ao trabalho que Marx prediz para o futuro" (Entre o Passado e o Futuro, p. 45). 
filosófico, pesou contra Marx o que pesara também contra todos aqueles que, no século XIX (Kierkegard, Nietzche), ousaram desafiar e investir contra a tradição. Para inverter a hierarquia conceitual da tradição, para por Hegel de cabeça para baixo, o preço pago como tributo foi o fato subreptício de ter que supor os próprios conceitos da tradição que se pretendia inverter. $\mathrm{O}$ desafio ambicioso que almeja destruir a tradição, ao operar sua crítica, o faz, todavia, nos quadros das categorias e conceitos justamente teorizados por essa tradição, sendo dela prisioneiro. ${ }^{4}$

Os fantasmas aterrorizantes do Totalitarismo totalitarismo pesam no espírito de Arendt catalisando sua reflexão. Por esses traumas ela direciona seu diálogo com a tradição revolucionária. O que Marx, ou os demais críticos da tradição no século XIX, diz ela, não foram potentes em viabilizar historicamente, a história mesma que se lhes seguiu, no XX, consumou. Eles, embora "retirassem do passado sua autoridade ousando pensar o futuro sem qualquer de suas orientações", situaram ainda a obra no campo das palavras, dos conceitos e, como Hegel, ainda se guiaram pelo "fio da tradição", pensando a "totalidade da história universal como um desenvolvimento contínuo". 5 Foi o século XX que rompeu o fio, quebrou a tradição, justo porque pôs em ação, realizou como fato, um fenômeno tanto impensável nos quadros conceituais da tradição de pensamento político quanto inajuizável pelos quadros da tradição de pensamento ético e jurídico:

\footnotetext{
4 "O fim de uma tradição não significa necessariamente que os conceitos tradicionais tenham perdido seu poder sobre a mente dos homens. Pelo contrário, às vezes parece que esse poder das noções e categorias cediças e puídas torna-se mais tirânico à medida que a tradição perde sua força viva e se distancia a memória de seu início; ela pode mesmo revelar toda sua força coerciva somente depois de vindo seu fim, quando os homens nem mesmo se rebelam mais contra ela. Essa, pelo menos, parece ser a lição da tardia colheita de pensamento formalista e compulsório, no século XX, que veio depois que Kierkgaard, Marx e Nietzche desafiaram os pressupostos básicos da religião tradicional, do pensamento político tradicional e da Metafísica tradicional invertendo conscientemente a hierarquia tradicional dos conceitos" (Idem).

5 "Kiekgaard, Marx e Nietzche situam-se no fim da tradição, exatamente antes de sobrevir a ruptura. O predecessor imediato deles foi Hegel. Foi ele que, pela primeira vez, viu a totalidade da história universal como um desenvolvimento contínuo, e essa tremenda façanha implicava situar-se ele mesmo no exterior de todos os sistemas e crenças do passado com reclamos de autoridade; implicava ser ele tolhido unicamente pelo fio de continuidade da própria história. O fio da continuidade histórica foi o primeiro substituto para a tradição (...) não para repudiar a tradição como tal, mas a autoridade de todas as tradições. Kierkgaard, Marx e Nietzche permaneceram hegelianos na medida em que viram a História da Filosofia passada como um todo dialeticamente desenvolvido; seu grande mérito está em que radicalizaram essa nova abordagem ao passado da única maneira em que ela podia ser ainda desenvolvida, isto é, questionando a tradicional hierarquia conceitual que dominara a Filosofia Ocidental desde Platão e que Hegel dera ainda por assegurada" (Idem).
} 
A ruptura brotou de um caos de perplexidades de massa no palco político e de opiniões de massa na esfera espiritual que os movimentos totalitários, através do terror e da ideologia, cristalizaram em uma nova forma de governo e dominação. A dominação totalitária como um fato estabelecido, que, em seu ineditismo, não pode ser compreendida mediante as categorias usuais do pensamento político, e cujos “crimes" não podem ser julgados por padrões morais tradicionais ou punidos dentro do quadro de referência legal de nossa civilização, quebrou a continuidade da História Ocidental. A ruptura em nossa tradição é agora um fato acabado. Nem o silêncio da tradição, nem a reação assestada contra ela no século XIX por pensadores podem jamais explicar o que efetivamente ocorreu. $\mathrm{O}$ caráter não-deliberado da quebra dá a ela uma irrevogabilidade que somente os acontecimentos, nunca os pensamentos, podem ter.

Pela consciência do olhar porque Hannah Arendt vê, e (res)sente, seu próprio tempo, assim perturbado por aquela experiência de paroxismo do poder como ela qualifica o Totalitarismo, o mal comporta um bem, algo assim como Homero dizia do jarro à soleira do palácio de Zeus no Olimpo, que contém tanto os bens quanto os males que ele reserva aos infortúnios da condição humana. ${ }^{6}$ Pois, argumenta a filósofa, aquele era um tempo também privilegiado, situando a abertura de novo princípio:

Em alguns aspectos, estamos em melhor posição. Não mais precisamos nos preocupar com seu repúdio pelos "filisteus educados", os quais, durante todo o século XIX, procuraram compensar a perda de autoridade autêntica com uma glorificação espúria da cultura. Hoje em dia, para a maioria das pessoas, essa cultura assemelha-se a um campo de ruínas que, longe de ser capaz de pretender qualquer autoridade, mal pode infundir-lhe interesse. Este fato pode ser deplorável, mas, implícita nele, está a grande oportunidade de olhar o passado com olhos desobstruídos de toda tradição, com uma visada direta que desapareceu do ler e do ouvir ocidentais desde que a civilização romana submeteu-se à autoridade do pensamento grego.

Momento histórico de um olhar, diz ela, privilegiado por visada direta, capaz de transparecer o tempo histórico, porque livrada sua percepção do filtro de autoridade com que o fio da tradição a estreitara, desde seu preenchimento pelos antigos romanos, nos últimos séculos antes da era cristã, até seu esvaziamento,

\footnotetext{
${ }^{6}$ Confira-se também o dito de Maquiavel nos Discorsi (I.6) que recria mimeticamente a formulação do topos antigo: "Se refletirmos com atenção sobre o que acontece neste mundo, ficaremos persuadidos de que não é possível remediar um inconveniente sem provocar algum outro (...) porque jamais se encontrará nada que seja perfeitamente puro, isento de quaisquer vícios ou perigos".
} 
nos alvores totalitários do XX. Por essa fórmula retórica de uma percepção de visada direta sobre o passado antigo Hannah Arendt condensa o anelo de um refrigério que alivie, senão cure, o pathos de seu tempo. Quer numa obra ( $A$ Condição Humana) como noutra (Entre o Passado e o Futuro), ela (re)inova o fio do passado originário: Grécia e Roma, democracia e república (re)vitalizamse, atualizam-se de novo nos diálogos dos modernos com os antigos.

Entre o fardo e o fio, tradição mais autoridade, em que presente estamos nós neste nosso lugar-tempo de que falamos? Qual nosso passado? Dispomos mesmo, neste nosso presente, de "olhos desobstruídos de toda tradição, de visada direta sobre o passado antigo", como augurava Hannah Arendt há meio século atrás? Ou, justo por sua reflexão, de Arendt, mas também de mais outros assim recentes (Leo Strauss, Cornelius Castoriadis, Jean-Pierre Vernant) que na segunda metade do último século (re)inovam as percepções da pólis, onde fomos parar?

Que razões, ou pelo menos que motivações, ou ainda mesmo que apelos, teríamos, então, nós, já na virada do segundo para o terceiro milênio, para também louvar(mos) a história? De que lugar social e por qual tempo histórico, discorriam os historiadores, antigo(s) mais moderno(s), acerca dessa modalidade de conhecimento e conscientização de mundo em que vivem e se movem os homens? Por qual lugar social e de qual tempo histórico ecoa(ría)mos nós, hoje, tais preceitos ressoados por vozes assim tão antigas quão modernas? Quão antigos ainda somos nós, os (pós?)modernos? Na travessia milenar da história humana, que afinidades nos aproximam, antigos e modernos, ou que descompassos nos distanciam?

Afinal, nos avatares de todos esses diálogos de antigos e modernos sobre a (escrita da) história, quem o Rei, quem o Coelho Branco, quem o sujeito, quem o objeto dos discursos histó(riográfi)cos? Quais seus princípios? Que legados de autoridade herdamos? Para nós, o fio não é ainda o fardo? Mas também, sem o fardo, qual o fio? Somos nós, neste nosso lugar e tempo, os sujeitos que avolumam esse fardo dando corpo à História? Somos nós que tecemos os fios que atam os nós e amarram o fardo, compondo a tradição e firmando sua autoridade? Que obra nos resta e que competência podemos assumir?

Então, sacudir o fardo ou (re)inovar o fio $?^{7}$ Talvez, antes, desfiar o fardo, desatar os nós que o, e também nos, prendem! Nem Rei de Copas nem Coelho Branco, quem sabe ... Alice!

${ }^{7} \mathrm{O}$ neologismo é inspirado nas análises que André Duarte teceu sobre o pensamento político de 
O conjunto de textos que compõe esta obra resulta do II Congresso Internacional "Antigos, modernos, Selvagens: diálogos franco-brasileiros de história e antropologia" realizado de 8 a 11 de setembro de 2009 por iniciativa conjunta do Departamento de História e do Departamento de Antropologia da FFLCH mais o Museu Paulista da USP. Ao ensejo das comemorações do Ano da França no Brasil e, em especial, dos 75 anos da Universidade de São Paulo, o evento, consolidando a longa tradição das interações acadêmicas estabelecidas pela FFLCH com o mundo acadêmico das universidades francesas, conferiu destaque especial a François Hartog, renomado historiador de prestígio internacional, que há já mais de uma década mantém regularmente nexos de pesquisa com o Brasil em várias instituições universitárias, ${ }^{8}$ lembrando-se ainda as orientações de Doutorado de vários professores brasileiros por ele conduzidas na EHESS, ${ }^{9}$ e que assim atualiza os nexos que originariamente foram promovidos quer por Fernand Braudel no Departamento de História quer por Claude Lévi-Strauss no Departamento de Antropologia. Em consonância com os domínios de estudos de François Hartog, definiram-se dois eixos de reflexões em que foram integrados os ensaios aqui apresentados: "Antigos e Modernos: reflexões sobre a escrita da história" e "História e Antropologia".

Hannah Arendt (cf. Moraes e Bignotto, 2001, p. 65-89).

${ }^{8}$ Departamento de História da FFLCH-USP por meio de Francisco Murari Pires e Carlos Alberto de Moura Zeron; Departamento de História da UFRJ por meio de Manoel Luiz Salgado Guimarães; Departamento de História da UFRGS por meio de Temístocles Américo Correa Cézar; e Departamento de História da UnB por meio de José Otávio Guimarães.

${ }^{9}$ Carlos Zeron, Temístocles Cézar, José Otávio Guimarães, Teodoro Rennó Assunção, Felipe Brandi e outros. 